\section{Evaluation of the Effects of DNase Treatment on Signal Specificity in RT-PCR and In Situ RT-PCR}

BioTechniques 25:630-638(October 1998)

\author{
ABSTRACT \\ In this study, the effects of DNase treat- \\ ment on the specificity of reverse transcrip- \\ tion (RT)-PCR have been investigated on \\ different samples, containing RNA, DNA, \\ $D N A / R N A$ and DNA/cDNA. This was to \\ evaluate the possibilities of getting specific \\ results in a direct in situ RT-PCR. All DNA \\ targets in the samples were eliminated after \\ $1 \mathrm{~h}$ of DNase treatment. However, some \\ DNA fragments still remained after both $1 \mathrm{~h}$
}

and overnight DNase treatment. When these fragments served as primers for amplification, nonspecific smears resulted. In samples containing small amounts of RNA, the RNA was affected by overnight treatment with DNase. Our conclusion is that the direct in situ RT-PCR is an unreliable method because the necessary DNase treatment induces nonspecific amplification, and no size-separation is possible. We conclude that the best way to perform an in situ RTPCR is to hybridize with a labeled specific probe after amplification is completed.

\section{INTRODUCTION}

In situ reverse transcription-polymerase chain reaction (RT-PCR) is a very sensitive method for detecting the exact site of mRNA production, even in cases with very low levels of mRNA. However, when using the more convenient direct method, e.g., incorporation of labeled nucleotides during the amplification instead of using a specific probe after RT-PCR as in traditional in situ hybridization, the specificity of the results might be questionable.

In a solution-phase RT-PCR, you can easily distinguish the products of interest by size-separation on an agarose gel and optimize the RT-PCR conditions to eliminate nonspecific signals. When the process is performed in tissue, no size-separation is possible.

The in situ RT-PCR is generally optimized by optimizing the set up in solution-phase PCR. However, it is not certain that this will give optimized conditions for tissue. Another way to enhance the probability of getting the desired product in the in situ RT-PCR is to raise the annealing temperature until no signal can be detected and then lower it until signal appears. These processes demand reliable primers that do not cause any nonspecific signals at any 
temperature close to the optimal temperature.

Despite all of these optimizing steps, the specific but unwanted signals from the genomic DNA present in the tissue remain. One way to eliminate these false-positive signals is to construct primers that overlap the boundary between two exons. The genomic DNA would then not include binding sites for these primers, and no such amplification would occur. Because construction of such primers is complicated, the most commonly used method to avoid signals from the genomic DNA is to treat the tissue with DNase (7). Since this treatment is necessary to eliminate all DNA, it is a very crucial part of the in situ RT-PCR protocol. Any remaining DNA would result in false RT-PCR signals and, theoretically, traces of partially degraded DNA might even enhance the nonspecific amplification $(3,7)$. Furthermore, the DNase procedure itself might affect the RNA (2).

Because the specificity of direct, in situ RT-PCR products is impossible to analyze, a series of solution-phase RTPCR experiments has been performed to examine what takes place in the RTPCR after DNase treatment. To mimic the in situ situation, the samples in these experiments contained DNA, RNA and protein rests.

\section{MATERIALS AND METHODS}

\section{Preparation of Nucleic Acids}

Nucleic acids were extracted from liver of female Sprague-Dawley rats (BeeKay, Stockholm, Sweden).

The RNA preparation was performed according to Chomczynski and Sacchi (1). Briefly, the tissue $(125 \mathrm{mg})$ was homogenized in $5 \mathrm{~mL}$ of homogenization solution containing guanidinium thiocyanate and phenol. RNA was chloroform-extracted, precipitated with isopropanol and washed with 70\% ethanol. Examination on a UV spectrophotometer gave a value for optical density (OD) $260 / \mathrm{OD}_{280}$ of 1.69 .

For the preparation of DNA, the tissue $(400 \mathrm{mg})$ was homogenized in 5 $\mathrm{mL}$ digestion buffer containing proteinase $\mathrm{K}(0.1 \mathrm{mg} / \mathrm{mL}$; Boehringer Mannheim GmbH, Mannheim, Germa- ny) and incubated at $50^{\circ} \mathrm{C}$ overnight. After phenol:chloroform (1:1) extraction, one-third of the aqueous phase was kept, probably containing both protein rests and nucleic acids (DNA/RNA 1). One-third was precipitated with isopropanol, collecting both RNA and DNA (DNA/RNA 2). The last third was precipitated with $100 \%$ ethanol and 7.5 $\mathrm{M} \mathrm{Na}{ }_{4} \mathrm{Ac}$, collecting only DNA, and carried through the rest of the protocol as described previously (8).

Examination of the preparations on a UV spectrophotometer resulted in an $\mathrm{OD}_{260} / \mathrm{OD}_{280}$ value for the DNA of 1.72 and for the two DNA/RNA samples 1.32 (1) and 1.65 (2).

\section{DNase Treatment}

The nucleic acids were incubated for $1 \mathrm{~h}$ or overnight at $37^{\circ} \mathrm{C}$ with $1 \mathrm{U}$ DNase I per $\mu \mathrm{g}$ of DNA/RNA (Boehringer Mannheim) followed by inactivation at $75^{\circ} \mathrm{C}$ for $5 \mathrm{~min}$.

\section{Reverse Transcription}

For the RT reaction, $2 \mu \mathrm{g}$ of nucleic acid were added to a mixture containing $200 \mathrm{U}$ moloney murine leukemia virus (MMLV) Reverse Transcriptase, 1× RT Buffer (Life Technologies, Gaithersburg, MD, USA), $0.5 \mathrm{mM}$ dNTP, $20 \mathrm{U}$ RNasin ${ }^{\circledR}, 2.5 \mathrm{mM}$ dithiothreitol (DTT) and $2.5 \mu \mathrm{M}$ oligo(dT) (Promega, Madison, WI, USA) or 7.5 $\mu \mathrm{M} 3{ }^{\prime}$-specific primer for $\beta$-actin. The total reaction volume was $20 \mu \mathrm{L}$. The mixture was heated to $65^{\circ} \mathrm{C}$ for $5 \mathrm{~min}$, before MMLV-RT, RNasin and DTT were added, and then incubated at $37^{\circ} \mathrm{C}$ for $1 \mathrm{~h}$.

\section{Polymerase Chain Reaction}

The $\beta$-actin primers were designed to distinguish the fragment originating in cDNA from the genomic fragment. The upper primer (5'-GTG GGG CGC CCC AGG CAC CA-3', nucleotides [nt] 1345-1366) is situated in exon 2, and the lower primer $\left(5^{\prime}\right.$-CTC CTT AAT GTC ACG CAC GAT TTC-3', nt 2413-2436) is in exon 4, generating a 1091-bp genomic fragment and a 540bp cDNA fragment (5).

From the RT reaction, $2 \mu \mathrm{L}$ (or the equivalent amount, $200 \mathrm{ng}$ nucleic acid) were used in the PCR. The $50-\mu \mathrm{L}$ reaction mixture contained $2.5 \mathrm{U}$ Taq DNA Polymerase, $1 \times$ Polymerization Buffer (both from Promega), $1 \mathrm{mM}$ $\mathrm{MgCl}_{2}, 0.2 \mathrm{mM}$ dNTP and $0.25 \mu \mathrm{M} \beta$ actin primers. The PCR program, $94^{\circ} \mathrm{C}$ for $40 \mathrm{~s}, 60^{\circ} \mathrm{C}$ for $45 \mathrm{~s}$ and $72^{\circ} \mathrm{C}$ for 90 $\mathrm{s}$ for 30 cycles, was performed on a Thermal Cycler 480 (Perkin-Elmer, Norwalk, CT, USA). The products were visualized on an agarose gel containing ethidium bromide.

All PCRs have been performed at least $3 \times$ with corresponding results.

\section{In Situ RT-PCR}

Rat livers were fixed in $4 \%$ formaldehyde overnight and embedded in paraffin. Sections, $5-\mu \mathrm{m}$ thick, were $(i)$ mounted on In Situ PCR Glass Slides (Perkin-Elmer), (ii) deparaffinized in xylene, (iii) rehydrated to nuclease-free water through graded fresh aqueous solutions of ethanol, (iv) treated with 0.2 $\mathrm{M} \mathrm{HCl}$ for $10 \mathrm{~min},(v)$ rinsed in phosphate-buffered saline (PBS), (vi) immersed in $0.01 \%$ Triton ${ }^{\circledR}$ X-100 (Sigma Chemical, St. Louis, MO, USA) in PBS for $3 \mathrm{~min}$ and (vii) rinsed in PBS. The sections were then treated with $2.5 \mu \mathrm{g} /$ $\mathrm{mL}$ proteinase $\mathrm{K}$ (Sigma Chemical) in TE (0.1 M Tris-HCl, 5 mM EDTA, pH 7.5) for $30 \mathrm{~min}$ at $37^{\circ} \mathrm{C}$. Digestion was stopped with $0.1 \mathrm{M}$ glycine for $5 \mathrm{~min}$.

The sections were then covered with $50 \mu \mathrm{L}$ DNase solution (1U/ $\mu \mathrm{L}$ DNase I in $0.1 \mathrm{M} \mathrm{NaAc}, \mathrm{pH} 5.0,5 \mathrm{mM}$ $\mathrm{MgSO}_{4}$ ), treated for $1 \mathrm{~h}$ or overnight and rinsed with distilled (d) $\mathrm{H}_{2} \mathrm{O}$. The sections were then placed in $0.25 \%$ acetic anhydride in $0.1 \mathrm{M}$ triethanolamine for $10 \mathrm{~min}$, followed by $20 \%$ acetic acid for $15 \mathrm{~s}$. After a wash in $\mathrm{dH}_{2} \mathrm{O}$ for $1 \mathrm{~min}$ and immersion in $100 \%$ ethanol for $1 \mathrm{~min}$, the sections were air-dried.

The RTs were performed as above, with oligo(dT) as primers, in a reaction volume of $50 \mu \mathrm{L}$. After completion of cDNA synthesis, the slides were rinsed in $\mathrm{dH}_{2} \mathrm{O}$ for $1 \mathrm{~min}$, immersed in $100 \%$ ethanol for $1 \mathrm{~min}$ and air-dried.

The PCR mixture included $1 \times$ PCR Buffer, $3 \mathrm{mM} \mathrm{MgCl}$, $0.2 \mathrm{mM}$ dNTP (Promega), $10 \mu \mathrm{M}$ digoxigenin (Dig)dUTP (Boehringer Mannheim), 0.8$\mu \mathrm{M} \beta$-actin primers and $2.5 \mathrm{U}$ Taq DNA polymerase. The sections were 


\section{Short Technical Reports}

covered with $40 \mu \mathrm{L}$ of this mixture, assembled in the preheated Assembly Tool (Perkin-Elmer) and then heated to $94^{\circ} \mathrm{C}$ for $5 \mathrm{~min}$ followed by $58^{\circ} \mathrm{C}$ for $45 \mathrm{~s}$ in a GeneAmp ${ }^{\circledR}$ In Situ PCR System 1000 Thermal Cycler (PerkinElmer). This was followed by 20 cycles as described above.

\section{Dig Detection}

After PCR, the slides were washed in $2 \times$ standard saline citrate (SSC) for 5 min at $40^{\circ} \mathrm{C}$ and rinsed in PBS for 2 min followed by Buffer I $(0.15 \mathrm{M}$ $\mathrm{NaCl}, 0.1 \mathrm{M}$ Tris- $\mathrm{HCl}, \mathrm{pH}$ 7.5) for 5 min. After incubation in 1\% Blocking Reagent (Boehringer Mannheim) for $30 \mathrm{~min}$, the slides were incubated with the anti-Dig-AP conjugate (Boehringer Mannheim) diluted $1: 350$ in $0.5 \%$ bovine serum albumin (BSA) in Buffer I for $90 \mathrm{~min}$. This was followed by further wash steps; first for 5 min in Buffer I and then $2 \times$ for 5 min in Buffer II (0.1 $\mathrm{M} \mathrm{NaCl}, 50 \mathrm{mM} \mathrm{MgCl} 2,100 \mathrm{mM}$ Tris$\mathrm{HCl}, \mathrm{pH}$ 9.5). The color was developed by incubation in freshly prepared colorsubstrate solution $[0.45 \mu \mathrm{g} / \mathrm{mL}$ nitro blue tetrazolium (NBT) chloride, 0.18 $\mu \mathrm{g} / \mathrm{mL}$ 5-Bromo-4-chloro-3-indolylphosphate (BCIP) (Boehringer Mannheim), $1 \mathrm{mM}$ Levamisole (Sigma Chemical) in Buffer II] for approxi- mately $3 \mathrm{~h}$. The color reaction was stopped by incubation in buffer containing $1 \mathrm{mM}$ EDTA, $10 \mathrm{mM}$ Tris- $\mathrm{HCl}$, $\mathrm{pH}$ 8.0. After washing in $\mathrm{dH}_{2} \mathrm{O}$ for 2 min, the slides were taken through increasing ethanol concentrations up to $100 \%$ ethanol and then air-dried. The slides were mounted in D.P.X. Neutral Mounting Medium (Sigma Chemical).

\section{RESULTS AND DISCUSSION}

In this study, the influence of DNase treatment on specificity of in situ RTPCR is demonstrated, and the origin of nonspecific results is investigated by solution-phase experiments on samples containing either RNA or DNA or both RNA and DNA.

The observation that DNase treatment enhances the degree of labeling in in situ RT-PCR, instead of reducing it, has been reported previously (3). Positive signals after DNase treatment were found even when no specific primers were used, which has been explained as a result of DNA repair performed by the Taq DNA polymerase (6). This study provides an additional mechanism for these signals, the priming of the PCR by the short DNA fragments remaining after DNase treatment.

In the in situ experiments, the RT-

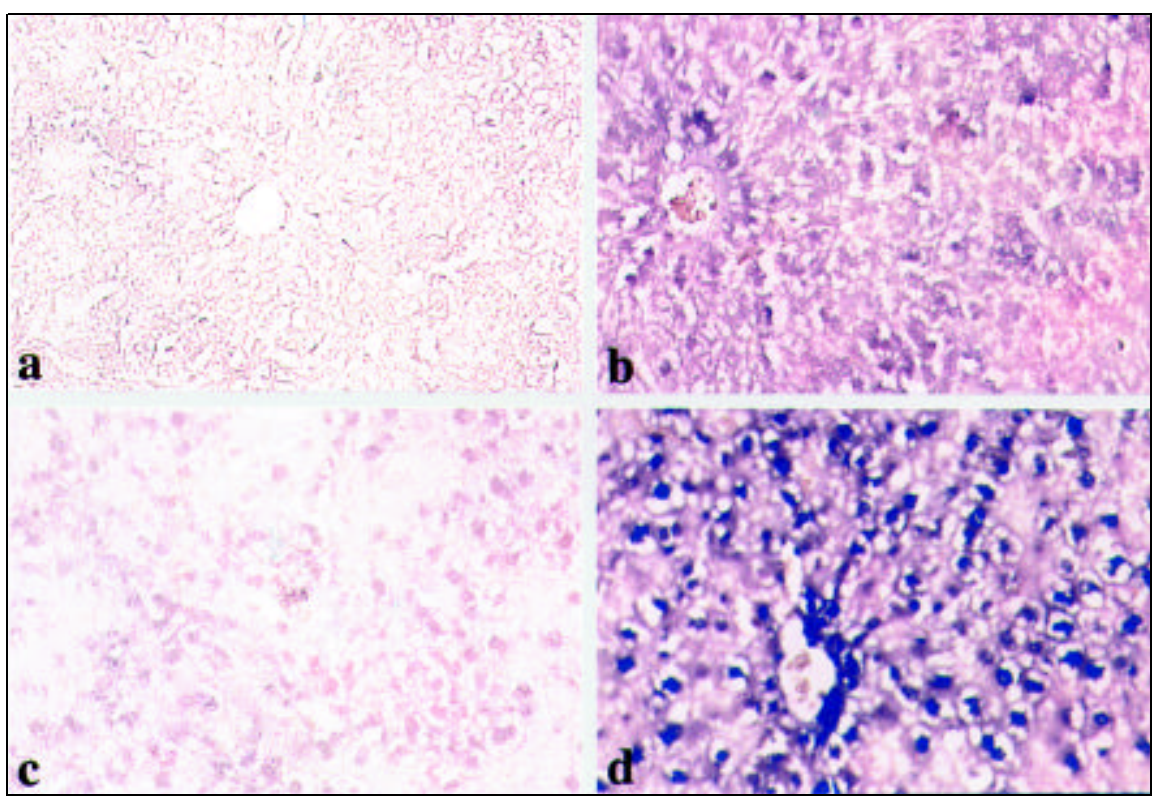

Figure 1. Results from in situ RT-PCR. In situ RT-PCR on rat liver. (a-c): RT-PCR performed without specific primers in the PCR: (a) Without preceding DNase treatment, (b) DNase-treated for $1 \mathrm{~h}$, (c) DNase-treated overnight and (d) RT-PCR with $\beta$-actin primers, DNase-treated for $1 \mathrm{~h}$.
PCR was performed without specific primers to evaluate the specificity of the experiment. A signal was detected in the sections treated with DNase for 1 $\mathrm{h}$ (Figure $1 \mathrm{~b}$ ) and also in the overnighttreated sections (Figure 1c); although, in the latter case, it was very weak. This was in contrast to the absence of any signal in the sections that were not DNase-treated at all (Figure 1a). Although the nonspecific signals were weak compared with the specific signal achieved when $\beta$-actin primers were used (Figure 1d), they could be very disturbing in investigations of mRNA of less abundance than mRNA coding for $\beta$-actin.

To clarify the origin of this nonspecific signal and to further investigate the effects of DNase treatment, a series of solution-phase experiments were set up using, as close as possible, the same conditions as in the in situ setup. Preparations of RNA and DNA from rat liver were performed to provide different situations for mimicking the in situ situation and to specifically evaluate the DNase effect on known compositions of nucleic acids.

The first step in the investigation was to verify the composition of the different samples. This was done by performing both an ordinary PCR and

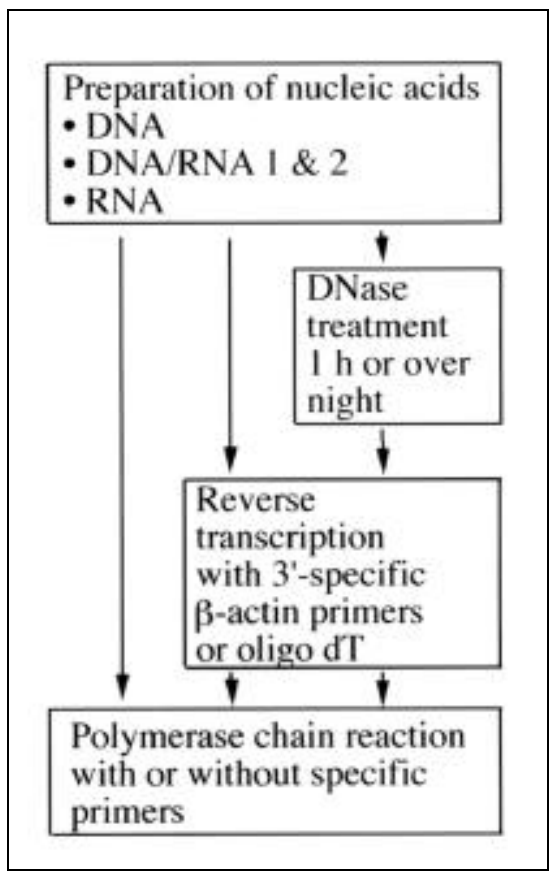

Figure 2. Schematic illustration of the performed experiments. 
an RT-PCR on all samples (Figure 3). The PCR gave no signal in the RNA sample, but in all samples where DNA was expected to be present, bands of the expected size (1091 bp) were seen. In some of these, an additional band that was the same size as the fragment expected from the RNA (540 bp) appeared. Our suggestion is that this might be an amplification of a processed pseudogene, a well-known phenomena in RT-PCR (4), even though no reports on such $\beta$-actin pseudogenes in rat have been published. In other words, the PCR confirmed the supposed DNA content of the samples. The RT-PCR also gave the expected results. The RNA sample gave a strong signal of $540 \mathrm{bp}$, and this band also appeared in the DNA/RNA preparations and in the mixtures of RNA and DNA together with the genomic fragment. When comparing the two DNA/RNA preparations, the RNA signal was weaker in the less-purified preparation (DNA/RNA 1). In the sample containing a 1:1 mixture of separately prepared DNA and cDNA, the RNA band almost completely dominated the amplification, and the signal from the genomic fragment was very faint, if at all visible. Even if this is the desired result in an RT-PCR, especially in tissue, it is not applicable in in situ RT-PCR because no separate cDNA synthesis is possible.

The RT was performed with both oligo(dT) and 3 '-specific, $\beta$-actin primers. When PCR results from the two different cDNA sources were com-

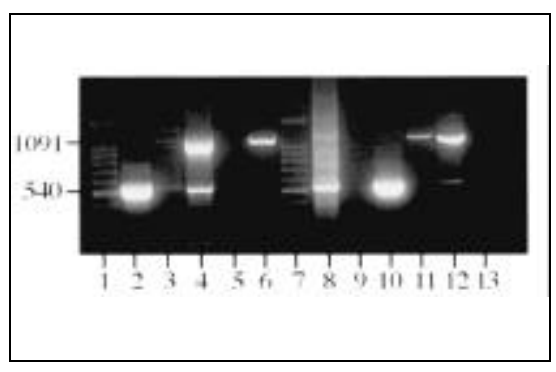

Figure 3. Results from PCR without DNase treatment. Lane 1: 100-bp ladder; lane 2: RTPCR of RNA; lane 3: RT-PCR of DNA/RNA 1; lane 4: RT-PCR of DNA/RNA 2; lane 5: PCR of RNA; lane 6: PCR of DNA; lane 7: 100-bp ladder; lane 8: RT-PCR of mixture of RNA and DNA; lane 9: unsuccessful PCR of mixture of RNA and DNA; lane 10: PCR of mixure of cDNA and DNA; lane 11: PCR of DNA/RNA 1; lane 12: PCR of DNA/RNA 2; lane 13: PCR without added nucleic acids, negative control. pared, the oligo(dT) gave specific signals, while the 3'-specific primers generated a smear in addition to the specific bands (data not shown). The difference in specificity was not seen when the samples were treated with DNase before the RT-PCR. This elimination of nonspecific amplification when using DNase indicates that the nonspecific amplification in the samples where 3 '-specific primer was used in the RT must originate from the DNA during the RT reaction. The observation that the RT-PCR with oligo(dT)s did not generate such smears also indicates their DNA origin, because the oligo(dT)s are probably not able to hybridize to DNA during RT because no poly(A) sequences are present.

The DNase efficiency and influence on the PCR specificity was investigated by exposing the samples to DNase for different periods of time, either $1 \mathrm{~h}$ or overnight. These incubation times were chosen because they are the extremes of the commonly used protocols.

The DNase-treated samples were investigated with both PCR and RT-PCR (Figure 4). The PCR would investigate the efficiency of the DNase treatment, and the RT-PCR would study the RNA stability and the altered specificity of the reaction.

The results showed no difference between the two DNase treatments regarding the efficiency of DNA target degradation, since no signals were recorded in any of the samples when no RT was performed (Figure 4, even numbers).

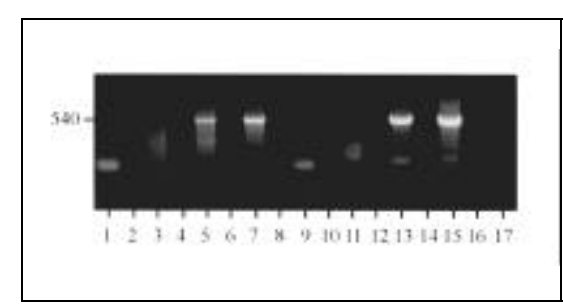

Figure 4. Results from PCR after DNase treatment. Times given indicate length of DNase treatment. Lanes 1-4: DNA/RNA 2; lane 1: RTPCR, overnight; lane 2: PCR, overnight; lane 3: RT-PCR, $1 \mathrm{~h}$; lane 4: PCR, $1 \mathrm{~h}$; lanes 5-8: mixture of DNA and RNA; lane 5: RT-PCR, overnight; lane 6: PCR, overnight; lane 7: RTPCR, $1 \mathrm{~h}$; lane 8: PCR, 1 h. Lanes 9-12: DNA; lane 9: RT-PCR, overnight; lane 10: PCR, overnight; lane 11: RT-PCR, 1 h. Lane 12: PCR, 1 h. Lanes 13-16: RNA; lane 13: RT-PCR, overnight; lane 14: PCR, overnight; lane 15: RT-PCR, $1 \mathrm{~h}$; lane 16: PCR, $1 \mathrm{~h}$.
However, the RT-PCR showed a greater diversity in the results. The less-purified DNA/RNA preparation, (DNA/RNA 1) gave almost no signals at all. One explanation for this might be that the smaller total content of RNA in this sample makes even a minor degradation of RNA result in a detectable loss of signal. Alternatively, the impurity of the sample makes the RNA less resistant to DNase. As this might reflect the situation with in situ techniques, one must be aware of the risk of degrading small amounts of RNA, in addition to the removal of genomic DNA.

The other DNA/RNA preparation gave no specific bands but produced a diffuse band of less than $100 \mathrm{bp}$ in the overnight-treated sample and a smear in the sample treated for $1 \mathrm{~h}$ (Figure 4 lanes 1 and 3). Because no amplification at all occurred without RT (Figure 4, lanes 2 and 4), it is obvious that these smears must have an RNA origin. The explanation for the lack of specific bands must be the absence of intact mRNA for synthesis of cDNA targets after the DNase treatment. However, even if the in situ results clearly show specific signals after DNase treatment for both $1 \mathrm{~h}$ (Figure 1d) and overnight (data not shown), the lack of signal in the solution-phase experiment indicates the risk of degrading RNA during DNase treatment when it is present in small amounts or affected in other ways.

The smear achieved in the $1 \mathrm{~h}$ DNase-treated sample instead of the expected 540-bp band was assumed to

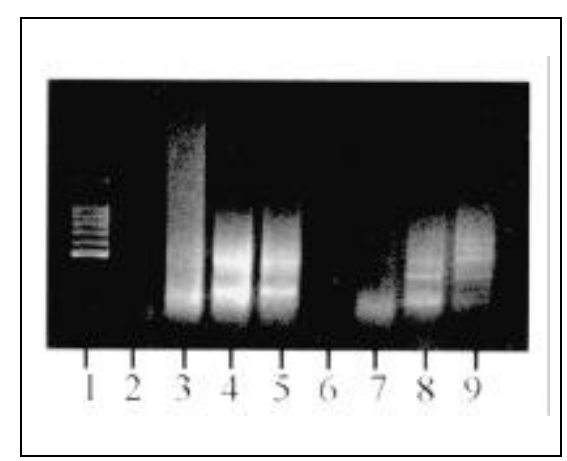

Figure 5. Results from RT-PCR without specific primers in the PCR. Times given indicate length of DNase treatment. Lane 1: 100-bp ladder; lane 2: DNA/RNA 2, overnight; lane 3: DNA/RNA 2, $1 \mathrm{~h}$; lane 4: mixture of DNA and RNA, overnight; lane 5: mixture of DNA and RNA, $1 \mathrm{~h}$; lane 6: DNA, overnight; lane 7: DNA, $1 \mathrm{~h}$; lane 8: RNA, overnight; lane 9: RNA, $1 \mathrm{~h}$. 
be a result of nonspecific amplification of smaller fragments of cDNA. The overnight treatment eliminated all RNA, except very short fragments, which act as templates for the RT and the amplification.

The RT-PCR of the DNase-treated DNA samples resulted in the same diffuse signals after overnight treatment and a smear after treatment for $1 \mathrm{~h}$ (Figure 4, lanes 9 and 11). This indicates some contamination of RNA that give no visible signals when larger amounts of DNA template are present.

The only specific signals achieved in this experiment were from the sample with equal amounts of mixed RNA and DNA, and from the RNA sample in which the 540-bp band was distinct. However, in comparison with the RTPCR without preceding DNase treatment, these signals are more nonspecif- ic, with the bands surrounded by smears. In addition to increased nonspecificity, the DNase treatment also seemed to affect the RNA in the mixed samples, which gave a weaker signal after the overnight treatment (Figure 4 lanes 5 and 7).

To establish the origin of these smears, the same RT-PCRs were performed but without specific primers. As expected, no specific bands were obtained (Figure 5). However, strong smears were visible in all DNase-treated samples except the overnight-treated DNA/RNA preparation and the overnight-treated DNA. The absence of smears in these two samples, where the RNA content is negligible, indicates that the smears in the other samples have cDNA as their template.

No smears appear in these experiments on samples that were not DNase-treated (data not shown), which is consistent with the in situ results (Figure 1a). Therefore, the amplification must be because of priming of the reaction by a cocktail of DNA fragments generated from partly degraded DNA. In this aspect, no difference between treating the sample with DNase for $1 \mathrm{~h}$ or overnight could be demonstrated in the solution experiments. This correlates to the in situ results in which a clearly visible signal appeared after DNase treatment, even if the signal after overnight DNase treatment was considerably weaker than after the 1-h treatment (Figure 1, b and c).

Because both the DNA primers and the cDNA originate in the same genomic DNA, priming ability of the short DNA fragments is rather obvious. Consequently, the sequence identity between "primer" and template is probably very high, leading to nonspecific amplification that might be difficult to eliminate.

The conclusion drawn from this work is that DNase treatment for $1 \mathrm{~h}$ or overnight eliminates all DNA that could serve as template for the PCR, but it might also affect the RNA. However, after DNase treatment, there are still DNA fragments left to serve as primers that generate a smear in RT-PCR.

To eliminate these nonspecific results due to DNA priming, specific primers with an annealing temperature higher than the one of this cocktail of
DNA primers must be constructed. Because constructions of such specific primers will generally prove to be very difficult, hybridization with a specific probe after the in situ RT-PCR is recommended for obtaining specific results.

\section{REFERENCES}

1.Chomczynski, P. and N. Sacchi. 1987. Single-step method of RNA isolation by acid guanidinium thiocyanate-phenol-chloroform extraction. Anal. Biochem. 162:156-159.

2.Huang, Z., M.J. Fasco and L.S. Kaminsky. 1996. Optimization of DNase I removal of contaminating DNA from RNA for use in quantitative RNA-PCR. BioTechniques 20:1012-1020.

3.Martínez, A., M.-J. Miller, K. Quinn, E.J. Unsworth, M. Ebina and F. Cuttitta. 1995. Non-radioactive localization of nucleic acids by direct in situ PCR and in situ RT-PCR in paraffin-embedded sections. J. Histochem. Cytochem. 43:739-747.

4.Menon, R.S., Y.-F. Chang, J. St. Clair and R.G. Ham. 1991. RT-PCR artifacts from processed pseudogenes. PCR Methods Appl. 1:70-71.

5.Nudel, U., R. Zakut, M. Shani, S. Neuman, Z. Levy and D. Yaffe. 1983. The nucleotide sequence of the rat cytoplasmic beta-actin gene. Nucleic Acids Res. 11:1759-1771.

6.Nuovo, G.J. 1997. PCR In Situ Hybridization: Protocols and Applications, 3rd ed., p. 271334. Lippincott-Raven, Philadelphia.

7.Sallstrom, J.F., I. Zehbe, M. Alemi and E. Wilander. 1993. Pitfalls of in situ polymerase chain reaction (PCR) using direct incorporation of labelled nucleotides. Anticancer Res. 13:1153.

8.Strauss, W.M. 1994. Preparation of genomic DNA from mammalian tissue, p. 2.2.1-2.2.3. In F.M. Ausubel, R. Brent, R.E. Kingston, D.D. Moore, J.G. Seidman, J.A. Smith and K. Struhl (Eds.), Current Protocols in Molecular Biology, John Wiley \& Sons, New York.

This work was supported by grants from Hjalmar Svensson Foundation and the Research Foundations of Sahlgrenska University Hospital. Address correspondence to Ms. Karin Ivarsson, Göteborg University, Department of Obstetrics and Gynecology, Sahlgrenska University Hospital, 41345 Göteborg, Sweden. Internet: reprod.genet @obgyn.gu.se

Received 27 October 1997; accepted 5 June 1998.

Karin Ivarsson and Birgitta
Weijdegård
Göteborg University
Göteborg, Sweden

Karin Ivarsson and Birgitta Göteborg University Göteborg, Sweden 